\title{
Anti-Inflammatory Actions of Pentacyclic Triterpenes
}

\author{
H. Safayhi ${ }^{1,2}$ and E.-R. Sailer ${ }^{1}$ \\ ${ }^{1}$ Department of Pharmacology, Institute of Pharmaceutical Sciences, University of Tuebingen, Auf der Morgenstelle 8, D-72076 Tuebingen, \\ Germany \\ ${ }^{2}$ Address for correspondence
}

Received: March 7, 1997; Revision accepted: July 10, 1997

\begin{abstract}
Pentacyclic triterpenes (PTs) as aglycones of saponins have a wide distribution in plants, and many of them have been used as anti-inflammatory remedies in folk medicine. This survey critically reviews the effects of PTs on proinflammatory mediator signalling pathways and data from experimental animal models and clinical trials. Because the knowledge of their actions is far from being satisfactory a critical summary of the partly promising but mostly scattered and preliminary data might promote productive research on chances and risks of PTs. Antiproliferative and anti-infectious actions and effects on intracellular cell signalling and hormone metabolism are beyond the scope of this short review, although such effects might also contribute to the understanding of the systemic anti-inflammatory actions of aglycones.
\end{abstract}

Key words: Pentacyclic triterpene pharmacology, terpenoids, sapogenins, inflammation, anti-inflammatory activity.

Abbreviations
AKBA: acetyl-11-keto- $\beta$-boswellic acid
BA(s): boswellic acid(s)
COX: cyclooxygenase
GA: glycyrrhetinic acid
GaIN: galactosamine
GL: glycyrrhizin
HETE: hydroxyeicosatetraenoic acid
HIV: human immunodefficiency virus
HLE: human leukocyte elastase
HSD: hydroxysteroid dehydrogenase
IFN: interferon
IL: interleukin
LO: lipoxygenase
LT: leukotriene
OA: oleanolic acid
PAF: platelet activating factor
PG: prostaglandins
PK: protein kinase
PPE: porcine pancreatic elastase
PT: pentacyclic triterpene(s)
ROS: reactive oxygen species
UA: ursolic acid

\section{Abbreviations}

BA(s): boswellic acid(s)

COX: cyclooxygenase

GA: glycyrrhetinic acid

GalN: galactosamine

GL: glycyrrhizin

Hydroxyeicosatetraenoic acid

HLE: human leukocyte elastase

HSD: hydroxysteroid dehydrogenase

LO: lipoxygenase

LT: leukotriene

OA: oleanolic acid

PAF: platelet activating factor

PG: prostaglandins

PK: protein kinase

ROS: reacti

ursolic acid

\section{Introduction}

In this review we present a survey on the antiphlogistic potential of a selected number of PTs (Fig. 1) for which the observed anti-inflammatory actions can be rationalized by data from in vitro mechanistic studies. We mainly consider studies which were carried out with purified compounds. We also try to reflect the reasonableness of the concentrations used in vitro and structure-activity relationships as far as data are available. Effects of saponins or crude extracts are only discussed if they contribute to the understanding of the actions of PTs.

\section{Inflammation}

The symptoms of an inflammation (redness, edema, heat, pain, and disturbed tissue function) are results of complex pathophysiological processes that include increased blood flow and vascular permeability, activation of humoral and cellular defence mechanisms, sensibilization and activation of nociceptors. These processes are mediated by a variety of signalling molecules produced by mast cells, macrophages, granulocytes, platelets, lymphocytes, nerve endings, endothel cells, etc., as well as by the activation of complement factors. The mediators belong to different chemical classes, such as biologically active amines (histamine, serotonin), proteins and peptides (hydrolytic enzymes, cytokines, growth factors, colony stimulating factors, complement factors, antibodies, kinines), activated oxygen species (superoxide anion, hydroperoxide, hydroxyl radicals), and lipids (platelet activating factor, prostanoids, leukotrienes). These mediators initiate, maintain, aggravate, and modulate the course of a vast number of human disorders. Besides the huge number of proinflammatory players, the complexity of such processes is further increased by the involvement of endogenous antiphlogistic and immunomodulatory mechanisms (e.g., the release of anti-inflammatory and immunosuppressive steroids from the adrenal cortex) and by the fact that among one class of mediators some members might act anti-inflammatory: e.g., 15(R)-HETE and lipoxins from the products of the arachidonic acid cascade or the interleukins 4,10 , and 13 from the cytokine family, which exert pro- and contrainflammatory actions depending on their involvement in specific immune responses. 


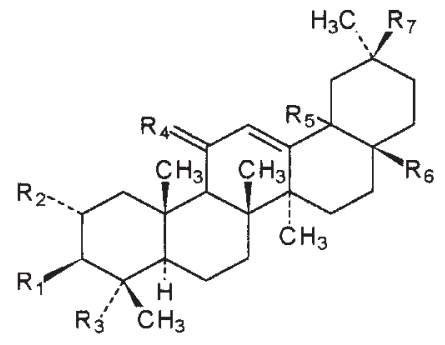

\begin{tabular}{|c|c|c|c|c|c|c|c|}
\hline & $\mathrm{R}_{1}$ & $\mathrm{R}_{2}$ & $\mathrm{R}_{3}$ & $\mathrm{R}_{4}$ & $R_{5}$ & $\mathrm{R}_{6}$ & $\mathrm{R}_{7}$ \\
\hline B-amyrin & $\mathrm{HO}$ & $\mathrm{CH}_{3}$ & $\mathrm{CH}_{3}$ & $2 \mathrm{H}$ & $\mathrm{BH}$ & $\mathrm{CH}_{3}$ & $\mathrm{CH}_{3}$ \\
\hline erythrodiol & $\mathrm{HO}$ & $\mathrm{CH}_{3}$ & $\mathrm{CH}_{3}$ & $2 \mathrm{H}$ & $\beta \mathrm{H}$ & $\mathrm{CH}_{2} \mathrm{OH}$ & $\mathrm{CH}_{3}$ \\
\hline oleanolic acid (OA) & $\mathrm{HO}$ & $\mathrm{CH}_{3}$ & $\mathrm{CH}_{3}$ & $2 \mathrm{H}$ & $\beta \mathrm{H}$ & $\mathrm{COOH}$ & $\mathrm{CH}_{3}$ \\
\hline hederagenin & $\mathrm{HO}$ & $\mathrm{CH}_{3}$ & $\mathrm{CH}_{2} \mathrm{OH}$ & $2 \mathrm{H}$ & $\beta \mathrm{H}$ & $\mathrm{COOH}$ & $\mathrm{CH}_{3}$ \\
\hline$\alpha$-hederin & Rha-Ara-O & $\mathrm{CH}_{3}$ & $\mathrm{CH}_{2} \mathrm{OH}$ & $2 \mathrm{H}$ & $\beta \mathrm{H}$ & $\mathrm{COOH}$ & $\mathrm{CH}_{3}$ \\
\hline crategolic acid & $\mathrm{HO}$ & $\mathrm{HO}$ & $\mathrm{CH}_{3}$ & 0 & $\beta \mathrm{H}$ & $\mathrm{COOH}$ & $\mathrm{CH}_{3}$ \\
\hline deoxoglycyrrhetol & HO & $\mathrm{CH}_{3}$ & $\mathrm{CH}_{3}$ & 0 & $\beta \mathrm{H}$ & $\mathrm{CH}_{3}$ & $\mathrm{CH}_{2} \mathrm{OH}$ \\
\hline $\begin{array}{l}18 \alpha-g l y c y r r h e t i n i c ~ a c i d \\
(18 \alpha-G A)\end{array}$ & $\mathrm{HO}$ & $\mathrm{CH}_{3}$ & $\mathrm{CH}_{3}$ & 0 & $\alpha \mathrm{H}$ & $\mathrm{CH}_{3}$ & $\mathrm{COOH}$ \\
\hline $\begin{array}{l}\text { 18ß-glycyrrhetinic acid } \\
(18 \beta-G A)\end{array}$ & $\mathrm{HO}$ & $\mathrm{CH}_{3}$ & $\mathrm{CH}_{3}$ & 0 & $\beta \mathrm{H}$ & $\mathrm{CH}_{3}$ & $\mathrm{COOH}$ \\
\hline glycyrrhizin & GICA-GICA-O & $\mathrm{CH}_{3}$ & $\mathrm{CH}_{3}$ & 0 & $\beta \mathrm{H}$ & $\mathrm{CH}_{3}$ & $\mathrm{COOH}$ \\
\hline carbenoxolone & Succo & $\mathrm{CH}_{3}$ & $\mathrm{CH}_{3}$ & o & $\beta \mathrm{H}$ & $\mathrm{CH}_{3}$ & $\mathrm{COOH}$ \\
\hline
\end{tabular}

Fig. 1 Structures of selected pentacyclic triterpenes (PTs).

\section{Principles of anti-inflammatory drug action}

Anti-inflammatory compounds can act on many steps of pathophysiological processes. For example, a compound might block the biosynthesis of proinflammatory mediators by direct interaction with a key enzyme (e.g., inhibition of cyclooxygenase-II) or by decreasing enzyme expression (e.g., steroidal anti-inflammatory compounds) or by reducing substrate levels (e.g., decreased release of arachidonic acid). Alternatively, or in addition, a compound can act by inhibiting the release of preformed, stored mediators (e.g., histamine release) or block mediator receptor interaction on target cells (e.g., leukotriene receptor antagonists). An anti-inflammatory compound may also act by immunostimulation (e.g., maturation of myeloid cells, stimulated phagocytosis) that in turn promotes an increased removal of the insulting signal molecules (organisms or, alternatively, by immunosuppression) that results in a less aggressive inflammatory response to allergen challenge. Thus, to evaluate the potential and the therapeutical index of a compound, qualified information on the mechanism and the selectivity of its action is needed.

\section{PT Actions on Mediator Signalling}

\section{Histamine release}

Histamine is a preformed proinflammatory mediator stored in mast cells and basophilic granulocytes. Once released, it contracts smooth muscles of bronchi and gut, but powerfully relaxes those of small blood vessels. It promotes edema formation and stimulates gastric acid secretion and sensory nerve endings.

GA at concentrations from 20 to $35 \mu \mathrm{M}$, but not $\mathrm{GL}$, inhibited dexamethasone induced increase in histamine content and histidine decarboxylase activity in mastocytoma P815 cells, and decreased histamine release from antigen stimulated rat mast cells (1). UA at concentrations of $1000 \mu \mathrm{M}$ or greater inhibited compound 48/80 induced histamine release from mast cells in vitro $(2,3)$. At $100 \mu \mathrm{M}$ UA was only a weak inhibitor $(26 \%)$, whereas other tested triterpenoids (i.e., betulinic acid, 3-O-acetylbetulinic acid, betulinaldehyde and ursolaldehyde) exerted no significant effects (2).

\section{Hydrolytic enzymes}

Under physiological conditions, endogenous and host macromolecules are intracellularly degraded by controlled, compartmented hydrolytic enzyme activities. Increased secretion of stored proteolytic enzymes from stimulated proinflammatory cells occurs in the course of pathophysiological processes. This sustained extracellular enzyme activity impairs functionally relevant macromolecules such as structure proteins, glycoproteins, and polysaccharides. Hydrolytic activities are also involved in complex regulatory processes like the release of biologically active compounds from precursor proteins, activation of complement factors, and degradation/activation of signal molecules, hormones, and receptors. 
Table 1 Effects of pentacyclic triterpenes on hydrolytic enzymes: human leukocyte elastase (HLE); $C_{3}$-convertase (C3C); hyaluronidase (HYU). $\mathrm{IC}_{50}$ or $K_{1}$ values are shown in $\mu \mathrm{M}$ and references in parentheses.

\begin{tabular}{|c|c|c|c|c|}
\hline enzyme & HLE & & $\mathrm{C} 3 \mathrm{C}$ & HYU \\
\hline $\mathrm{OA}$ & 6 & (5) & $>200$ & $300 \quad(9)$ \\
\hline Uvaol & 16 & (5) & & \\
\hline Erythrodiol & 17 & (5) & & \\
\hline Hederagenin & 62 & (5) & & $280 \quad$ (9) \\
\hline
\end{tabular}

a A nonstandardized extract declared as boswellic acid was tested.

Human leukocyte elastase (HLE), which is produced and released by stimulated PMNL, is a highly aggressive and destructive serine protease. It has been suggested that HLE plays a role in several chronic disorders like pulmonary emphysema, cystic fibrosis, bronchitis, acute respiratory distress syndrome, glomerulonephritis, hepatitis, and rheumatic arthritis. HLE is believed to participate in the destruction of elastin, which is the primary elastic component of the lungs, blood vessels, and many other organs, and further proteins like fibronectin, laminin, collagen, proteoglycans, and immunoglobulins. The hydrolysis of blood vessel elastin by HLE promotes the transendothelial migration of stimulated proinflammatory cells. As shown in Table 1, UA, OA, BAs (especially AKBA), and uvaol (Fig. 2) in concentrations less than $20 \mu \mathrm{M}$ inhibited HLE in vitro, whereas other PTs were less active $(4,5)$. The effect of PTs on HLE is the result of the interaction of these compounds with the extended substrate binding site of the enzyme. The type of inhibition is competitive or noncompetitive depending on both the substrate length and the substituents on the pentacyclic ring system $(4,5)$.

$\mathrm{OA}$ and hederagenin (with $\mathrm{IC}_{50}$ values of 5 and $41 \mu \mathrm{M}$ ) inhibited the serin protease porcine pancreatic elastase (PPE)(6). UA inhibited PPE and trypsin with $K_{\mathrm{i}}$ values of 180 and $157 \mu \mathrm{M}$, re- spectively (4). The pancreatic serine protease chymotrypsin was weakly inhibited by $\mathrm{UA}$ in vitro $\left(K_{\mathrm{i}}\right.$ and $\mathrm{IC}_{50}$ values of 37 and $70 \mu \mathrm{M})$, but not by AKBA in concentrations up to $100 \mu \mathrm{M}(4,5)$. Application to rats of both the B. serrata gum resin and BA containing extracts thereof reduced glycosaminoglycan biosynthesis and degradation (7).

Strikingly, the gum resin was found to afford more therapeutic value than the BA extract in producing increased lysosomal stability and reduced $\beta$-glucuronidase activity (8). Effects on hyaluronidase of $\mathrm{OA}$, hederagenin, and escinol were reported, but the $\mathrm{IC}_{50}$ values for this effect were exorbitantly high (6). Effects of some PTs (e.g., OA ad BAs) on $\mathrm{C}_{3}$-convertase were observed but in these studies the inhibitors were used in concentrations greater than $200 \mu \mathrm{M}(9,10)$. A series of PTs inhibited immunohemolysis promoted by the classical complement pathway. Actions with $\mathrm{IC}_{50}$ values in the range of 10 to $50 \mu \mathrm{M}$ were reported for $\mathrm{UA}, \beta$-BA, and crategolic acid, whereas GA and $O A$ were less and $\beta$-amyrin and friedelin were not inhibitory (11).

In the alternative pathway high concentrations of $\beta$-BA (50 and $100 \mu \mathrm{M}$ ) exerted anticomplementary activity, whereas UA, $\mathrm{OA}$, crategolic acid, and GA were less active (11). It was suggested

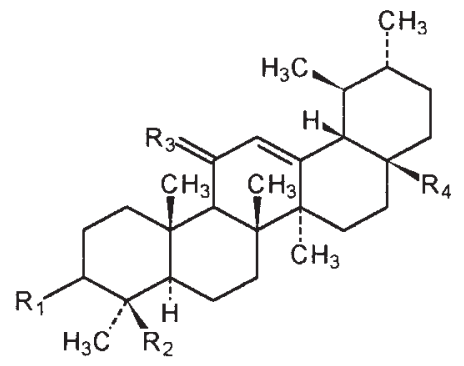

\begin{tabular}{l|l|l|l|l} 
& $\mathrm{R}_{1}$ & $\mathrm{R}_{2}$ & $\mathrm{R}_{3}$ & $\mathrm{R}_{4}$ \\
\hline$\alpha$-amyrin & $\beta \mathrm{HO}$ & $\mathrm{H}$ & $2 \mathrm{H}$ & $\mathrm{H}$ \\
\hline uvaol & $\beta \mathrm{HO}$ & $\mathrm{H}$ & $2 \mathrm{H}$ & $\mathrm{CH}_{2} \mathrm{OH}$ \\
\hline ursolic acid (UA) & $\beta \mathrm{HO}$ & $\mathrm{H}$ & $2 \mathrm{H}$ & $\mathrm{COOH}$ \\
\hline $\begin{array}{l}\text { acetyl-11-keto- } \beta \text {-boswellic } \\
\text { acid (AKBA) }\end{array}$ & $\alpha \mathrm{AcO}$ & $\mathrm{COOH}$ & $\mathrm{O}$ & $\mathrm{H}$ \\
\hline $\begin{array}{l}\text { 11-keto- } \beta \text {-boswellic acid } \\
\text { (KBA) }\end{array}$ & $\alpha \mathrm{HO}$ & $\mathrm{COOH}$ & $\mathrm{O}$ & $\mathrm{H}$ \\
\hline$\beta$-boswellic acid & $\alpha \mathrm{HO}$ & $\mathrm{COOH}$ & $2 \mathrm{H}$ & $\mathrm{H}$
\end{tabular}


that the effects of PTs on complement activation might be due to the inhibition of $\mathrm{C}_{3}$-convertase, which probably is the reflection of a more general inhibition of serine proteases $(4,11)$.

\section{Cytokines}

Cytokines (tumor necrosis factors, interleukins [ILs], interferons [IFNs], colony stimulatory factors), which are released by activated cells, have a wide range of effects that regulate immune responses and inflammatory processes in a sustained way. In target cells they modulate pathophysiologically relevant cell functions, such as adhesion molecule expression, cell growth, division, differentiation or programmed cell death, immunoglobulin production, chemotaxis.

From data of an early observation that the $i . v$. administration of GL induced an antiviral activity in mice serum, it was deduced that GL induced IFN, probably IFN $\gamma$, production. GA promoted antiviral activity was more moderate and not dose-dependent (12). GL increased in concentrations of 10 to $100 \mu \mathrm{g} / \mathrm{ml}$ (about 12 to $120 \mu \mathrm{M}$ ) IFN $\gamma$ production in concanavalin A stimulated human peripheral lymphocyte-macrophage cocultures but not in resting cells (13). In GL treated cells RNA and protein synthesis were increased and the DNA synthesis was reduced. GL $(200 \mu \mathrm{g} / \mathrm{ml}$, about $240 \mu \mathrm{M}$ ) prolonged the duration of the growth response of T-lymphocytes, which were stimulated by anti-CD3 monoclonal antibody, concanavalin A, or A23187 plus PMA, along with increased IL-2 production and IL-2 receptor expression. Since GL did not modulate receptor mediated protein tyrosine phosphorylation or $c$-fos transcription, it was suggested that the effect of GL is due to an interaction with a late step of the signal transduction pathway for IL-2 production (14). However, in immature thymocytes GL accelerated IL-2 production on the one hand and inhibited growth response on the other hand. These actions in immature cells were accompanied by an inhibition of tyrosine phosphorylation of p40 and c-fos expression (15).

\section{Reactive oxygen species and lipid peroxidation in vitro}

In vivo, reactive oxygen species (ROS), such as NADPHoxidase-generated $\mathrm{O}_{2}^{-}$and enzymatic and non-enzymatic products from $\mathrm{O}_{2}^{-\cdot}$ are important factors of the cellular defence mechanisms in phagocytes. Substrate conversion by mono- and dioxygenases also contributes to the production of radicals and peroxides. A sustained overboarding production of radicals and peroxides may exhaust the capacity of endogenous scavengers and anti-oxidative mechanisms and lead to an impairment of functionally relevant structures. In in vitro and in vivo assay systems radicals and peroxides are produced by chemical systems or by microsomal monooxygenase catalyzed metabolism of drugs.

$\mathrm{GL}$ ( $60 \mathrm{nM}$ to $6 \mu \mathrm{M}$ ) inhibited ROS generation in phagocytosing human neutrophils in vitro, but did not exert ROS scavenger activity in the xanthine/xanthine oxidase (XOD) system or impair neutrophil phagocytosis and chemotaxis (16). High concentrations (about 200 to $2000 \mu \mathrm{M}$ ) of $18 \beta$ - and $18 \alpha$-GA prevented $\mathrm{CCl}_{4}$ and GalN induced cytotoxicity in primary cultured rat hepatocytes and Fe/ADP and $\mathrm{Fe} /$ ascorbate promoted lipid peroxidation, but were ineffective at $20 \mu \mathrm{M}$. Strikingly, GA, in contrast to vitamin $\mathrm{E}$, did not suppress auto-oxidation of linoleic acid. It was suggested that the action of GA was elicited only in the case with lipids constituting the membrane structure (17).
AKBA, $\beta$-BA, UA, and amyrin (up to $100 \mu \mathrm{M}$ ) did not block XOD in our hands. In contrast, the nonselective redox-type dioxygenase inhibitor NDGA almost abolished XOD activity at $1 \mu \mathrm{M}$. In line with this observation, acetyl-BAs did not modulate Fe/ascorbate-induced lipid peroxidation in vitro in concentrations up to $400 \mu \mathrm{M}$ (18). In contrast, the preincubation of microsomes with OA (from $20.7 \mu \mathrm{M}$ to $249 \mu \mathrm{M}$ ) prevented $\mathrm{Fe} / \mathrm{ADP}$ and $\mathrm{Fe} / \mathrm{ascorb}$ ate induced lipid peroxidation and more moderately $\mathrm{CCl}_{4}$ promoted peroxidation (19). However, no substantial concentration response dependency was observed in this study. A moderate effect (about $20 \%$ protection) of OA $(240 \mu \mathrm{M})$ was measured in adriamycin (ADR) induced lipid peroxidation of heart microsomes and a 35-50\% protection with liver microsomes. A preincubation of $240 \mu \mathrm{M}$ OA with liver microsomes increased subsequent protection of heart microsomes against ADR induced lipid peroxidation to about $70 \%$ suggesting that a liver microsome generated metabolite of OA possesses scavenger activity (20).

\section{Lipid-derived mediators}

Lipid-derived mediators exert many potent proinflammatory effects. Some prostaglandins (e.g., $\mathrm{PGD}_{2}$ ) cause bronchoconstriction, mucus secretion, vasodilatation, and vasopermeability. Cysteinyl-leukotrienes ( $\mathrm{LTC}_{4}, \mathrm{LTD}_{4}$ and $\mathrm{LTE}_{4}$ ) are putative bronchoconstrictors and stimulators of vasopermeability and vasodilatation. $\mathrm{LTB}_{4}$ is a potent stimulator of leukocytes and promotes, among further effects, chemotaxis. Additionally, in some cells distinct cyclooxygenase (COX) and lipoxygenase (LO) products were reported to modulate proliferation and differentiation. PAF (platelet activating factor) causes bronchoconstriction, platelet activation and leukocyte chemotaxis. Effects of PTs on the arachidonic acid cascade have been studied incompletely, and in case of PAF signalling and COX-II activity no data are available yet.

UA (at $1 \mu \mathrm{M}$ ), a dihemiphthalate of the oleanane series $\left(\mathrm{IC}_{50}=\right.$ about $6 \mu \mathrm{M}$ ), amyrin, amyrin derivatives and GA (producing $30 \%$ inhibition at $100 \mu \mathrm{M}$ and with no effect at $10 \mu \mathrm{M}$ ) were reported to inhibit the conversion of exogenous substrate by 5 LO and/or COX (21-24). However, the data of these studies do not unambiguously demonstrate the inhibition of COX or 5-LO by these PTs. Thus, the postulated actions on prostaglandin and leukotriene synthesis have to be confirmed by appropriate methods.

A BA containing crude extract and BAs, especially AKBA, inhibited 5-LO product formation from endogenous arachidonic acid in intact neutrophils, as well as from exogenous substrate in a cell-freee system and the activity of purified human 5-LO with $\mathrm{IC}_{50}$ values of $1.5 \mu \mathrm{M}, 8 \mu \mathrm{M}$, and $15 \mu \mathrm{M}$, respectively ( 18 , 25, 26). Many PTs (including UA, OA, amyrin), but not 4-ring compounds, bind to 5-LO protein. However, only PTs from the BA series possessing an 11-keto group in addition to a hydrophilic function at C-4 exert potent 5-LO inhibitory activity $(26-28)$. GA was reported to be active in ionophore-stimulated cells, although this action was attributed to inhibition of PLA (29). In contrast, GA was found not to inhibit PG release from phagocytosing leukocytes (30). In our hands, $18 \beta$-GA exerted an LT biosynthesis inhibitory activity in intact neutrophils at higher concentrations $\left(\mathrm{IC}_{50}>10 \mu \mathrm{M}\right)$, but the interpretation of its effect was hampered by a concomitant impairment of cell viability (19). High concentrations of $18 \beta$-GA also inhibited the conversion of exogenous arachidonic acid by 5 -LO in cell-free 
systems by a competitive mechanism (observations not published).

In vivo, carbenoxolone treatment was associated with elevated gastric luminal concentrations of $\mathrm{PGE}_{2}$ in peptic ulcer patients (31). It was suggested that carbenoxolone inhibits the activities of 15-hydroxy-PG-dehydrogenase and $\Delta^{13}$-PG-reductase and that the resulting decreased inactivation of cytoprotective PGs synthesized within the gastric mucosa contributes to the postulated ulcer healing effect of carbenoxolone $(32,33)$. In addition, carbenoxolone inhibited the increased gastric mucosal release of $\mathrm{LTC}_{4}$, that was induced by intragastric installation of ethanol (34).

\section{Experimental Animal Models}

Systemic anti-inflammatory effects of PTs might be due to their actions on mediator signalling discussed so far. However, distinct irritants given, interaction with steroid hormone metabolism, kinases, phosphatases, virus replication and tumor cell proliferation, though not discussed in this short review, might also contribute to anti-inflammatory actions. Examples of such effects are the inhibition of $11 \beta$-HSD by GA in the nanomolar range and with less efficiency by OA $(35-37)$, the inhibition of proteinkinases in the lower micromolar range by GA, UA, OA, and betulinic acid (38), and the inhibition of virus replication by GA and betulinic acid derivatives (Fig. 3) $(39,40)$.

\section{Hepatoprotective activity}

Experimental hepatitis in animals is induced by different mechanisms. Heavy metals and toxic metabolites of drugs, the latter are radicals and peroxides generated by microsomal enzymes, impair hepatocytes directly whereas the effects of galactosamine (GalN) and endotoxin (LPS) are promoted by inhibition of anabolic processes and activation of cellular defence mechanisms including immunological responses.

Oral administration of $18 \beta$-GA, but not of GL, protected rats against GalN induced increase in serum transaminases, whereas both GA and GL were active when administered i.p. (41). GL in rats (i. v. or i. p.) had no protective effect on hepatic<smiles>[R]C12CC[C@H](C(=C)C)[C@@H]1[C@@H]1CC[C@@H]3[C@](C)(CC[C@H]4C(C)(C)[C@@H](O)CC[C@]34C)[C@@]1(C)CC2</smiles>

\begin{tabular}{l|l} 
& $\mathrm{R}$ \\
\hline lupeol & $\mathrm{CH}_{3}$ \\
\hline betulin & $\mathrm{CH}_{2} \mathrm{OH}$ \\
\hline betulinic acid & $\mathrm{COOH}$
\end{tabular}

Fig. 3 injury induced by LPS but prevented the effects of $\mathrm{CCl}_{4}$ and allyl formate (42).

A mixture of acetyl-BAs prevented GalN and LPS induced liver damage in mice (43). Inhibition of HLE activity in addition to decreased formation of cysteinyl-LTs has been suggested to be the rationale for liver protection by BAs (5). OA protected rats against $\mathrm{CCl}_{4}$-induced acute liver injury (44) and $\mathrm{CCl}_{4}$ /alcoholinduced cirrhosis (45) and $\mathrm{CF}-1$ mice against hepatotoxic effects of $\mathrm{CCl}_{4}$, acetaminophen, cadmium, bromobenzene, thioacetamide, furosemide, phalloidin, colchicine, GalN, and LPS, but was ineffective against allyl alcohol $(46,47)$. Protection against acetaminophen was not evident until $24 \mathrm{~h}$ after 5 . c. injection of $O A$ and lasted for $72 \mathrm{~h}$ (48). It was suggested that $O A$ decreases the formation of toxic metabolites of acetaminophen and increases detoxication since in mice OA suppressed liver microsomal cytochrome P450 isoenzymes CYP1A and CYP2A and increased hepatic content of metallothionein $(49,50)$. Substantial protective effects against $\mathrm{CCl}_{4^{-}}$, acetaminophen-, and $\mathrm{Cd}$-induced liver injury were also observed with $\alpha$-hederin and UA. Uvaol protected against $\mathrm{CCl}_{4}$ and $\mathrm{Cd}$-induced hepatotoxicity, GL, $\alpha-\mathrm{GA}$, and $\beta$-GA against acetaminophen, whereas hederagenin and $19 \alpha$-hydroxyasiatic acid did not protect against any of the toxicants (51).

\section{Acute inflammatory animal models}

Anti-inflammatory effects in animal models were reported for a number of PTs. Most frequently the increase in paw volume of rats or mice in response to injection or implantation of irritants (carrageenan, dextran, cotton pellets, formaldehyde, serotonin, bacteria, etc.) has been measured. Since edema generation is most prominently promoted by proinflammatory PGs direct and indirect COX-II inhibitors (steroidal and nonsteroidal antiinflammatory drugs) are often used as model compounds in these tests. It is noteworthy that many proinflammatory cytokines as well as many chemical and biological irritants upregulate COX-II expression.

GA and derivatives $(30,52), \mathrm{OA}(53)$, betulin, betulinic acid, UA (54), and a crude BA containing extract from B. serrata gum resin $(10,55,56)$ were reported to inhibit experimental edema in animals. Strikingly, the inhibitory effects of betulin, betulinic acid, and UA in carrageenan and serotonin paw edema tests could be blocked by progesterone, actinomycin D, and cycloheximide (54) suggesting that the anti-inflammatory actions of these PTs are mediated by mechanisms related to glucocorticoid receptor activation and MRNA and protein biosynthesis. UA inhibited phorbol ester induced edema of mouse ears $(57,58)$. The anti-inflammatory activity in this model seems to be common to many PTs (including $\alpha$-and $\beta$-amyrin, UA, OA, hederagenin, GA, lupeol, lupeol-3-acetate, betulin, betulinic acid, and their saponins), which were effective with comparable $\mathrm{ED}_{50}$ values in the range from 0.1 to $1.3 \mu \mathrm{mol}$ per ear $(59,60)$. Topical applications of dihemiphthalate derivatives of the oleanane series, but not GA and deoxyglycyrrhetol, reduced arachidonic acid-induced ear edema in mice in parallel to a decreased $\mathrm{PGE}_{2}$ and $\mathrm{LTB}_{4}$ formation with $\mathrm{ID}_{50}$ values of about $2 \mathrm{mg}$ per ear (61). Inhibition of dextran induced leukocyte migration into the pleural space by GA (32) and by a crude BA containing extract from $B$. serrata gum resin (65) were reported. 


\section{Immunomodulation}

Saikogenin D, as well as saikosaponin a and d, augmented nonspecific protection in mice against Pseudomonas aeruginosa infection in terms of increased survival (63). Soyasapogenol E (Fig. 4) was demonstrated to inhibit TPA induced EpsteinBarr virus early antigen activation (64). A crude ethanolic extract of $B$. carterii gum resin decreased mortality in mice to which a suspension of E.coli had been administered intraperitoneally (65). This in vivo observation was suggested to be due to stimulated phagocytic activity by the lipophilic nonsaponifiable fraction. A nonstandardized BA containing extract displayed either immunosuppressive or immunomodulating actions in mice depending on the dosage schedules and timings of administration in relation to antigen stimulation, whereas a preincubation of peritoneal macrophages at concentrations from 15 to $62 \mu \mathrm{g} / \mathrm{ml}$ stimulated the phagocytic activity in vitro (66).

\section{Clinical Studies}

The GA derivative carbenoxolone has been used as an antiulcerative drug (for monographs see 67,68 ). In Japan, a preparation of GL combined with glycine and cysteine has been widely used as an antihepatitis drug. Hematological and histological improvement following commencement of GL has been reported in patients with chronic hepatitis (for references see 12). Since GL was observed to inhibit virus growth and to promote inactivation of virus particles ( 40 ), it was also used for the prevention of recurrence of hepatitis B after liver transplantation (69). However, the therapeutic index of GA and derivatives is limited due to potent mineralocorticoid actions, which are mediated by interaction with steroid metabolism. OA has been marketed in China as an oral drug for human liver disorders and was reported to have been used successfully (for review see 70 ). Promising preliminary results have been

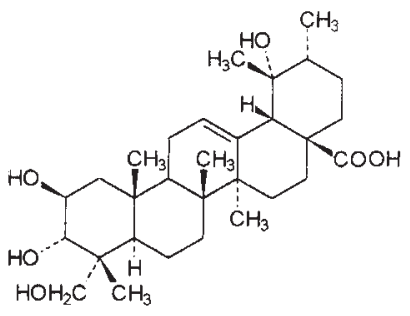

19a-hydroxy-asiatic acid

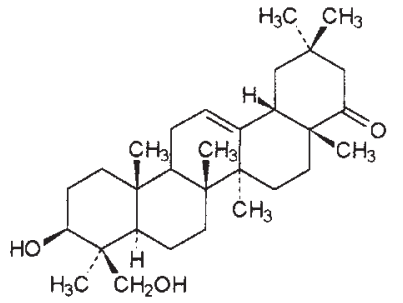

soyasapogenol $E$

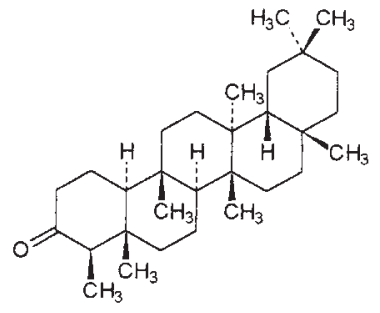

friedelin

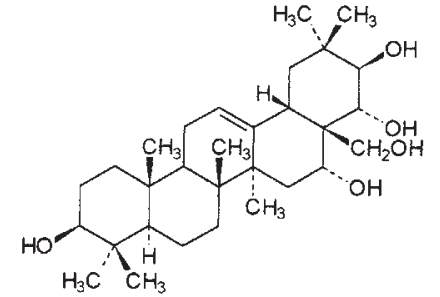

escinol obtained with BA containing preparation in first clinical studies. In line with the in vitro observations, $p . o$. application of a commercial crude chloroform/methanol extract from the $B$ serrata resin with a nonstandardized content on BAs inhibited increased urinary cysteinyl-LT excretion in astrocytoma patients and reduced peritumoral brain edema volumes (71). In a prospective, controlled clinical study, a 7-day treatment of patients with malignant glioma resulted in a significant reduction of perifocal edema, but no reduction of tumor sizes (72). The 5-LO inhibition is proposed to be of pharmacotherapeutic value in brain tumor patients with increased LT biosynthesis. In some clinical studies (open and placebocontrolled) the use of the commercial chloroform/methanol $B$. serrata gum resin extract yielded promising results in a limited number of patients with chronic polyarthritis $(73,74)$. A nonstandardized, powdered preparation from the gum resin of B. serrata, which contained BAs, was as effective as sulfasalazine in treating ulcerative colitis as observed in an open, non-randomized clinical trial (75). Since these observations are based on the results of pilot studies with few patients (14 to 39), data from state-of-the-art clinical trials with standardized $B A$ preparations and a greater number of patients are needed to establish the probable value of BA containing drugs for the treatment of severe human diseases.

\section{Summary and Perspectives}

There are many reports on biological actions of PTs, which could be relevant for pharmacological effects including their anti-inflammatory properties. Data from in vitro studies could help to understand the mechanisms of their actions. It is, however, remarkable that many observations reported were obtained in studies using exorbitantly high concentrations. Because of the limited solubility and nonselective actions of high concentrations of lipophilic compounds the interpretation of the results must be critically reconsidered in order to evaluate the practical implications of a probable use in vivo. In summary, we suggest that in vitro effects produced with concentrations much greater than $10 \mu \mathrm{M}$ will hardly have a practical relevance. But there are reports also on highly interesting actions for a limited number of PTs at reasonable concentrations in vitro, which may help to explain pharmacological actions and side effects in vivo. In general, however, the current knowledge on effects of PTs and structure-activity relationships is preliminary. In conclusion, there exists promising data suggesting that PTs are a class of compounds with highly interesting biological effects worth to be studied more carefully. The low acute toxicity of these natural compounds and hints from SAR studies, which suggest that defined substitutents on the lipophilic 5-ring backbone can increase selectivity and potency of a desired action, indicate that PTs might provide a rich natural resource of lead compounds for drug development.

\section{References}

${ }^{1}$ Imanishi, N., Kawai, H., Hayashi, Y., Yatsunami, K., Ichikawa, A. (1989) Biochem. Pharmacol. 38, 2521 -2526.

2 Tsuruga, T., Chun, Y.-T., Ebizuka, Y., Sankawa, U. (1991) Chem. Pharm. Bull. 39, 3276-3278.

3 Rajasekaran, M., Sudhakaran, C., Pradhan, S.C., Bapna, J. S., Nair, A. G. R. (1989) J. Drug Dev. 2, 179-182.

4 Ying, Q. -L., Rinehart, A. R., Simon, S. R., Cheronis, J. C. (1991) Biochem. J. 277, 521-526. 
5 Safayhi, H., Rall, B., Sailer, E. -R., Ammon, H. P. T. (1997) J. Pharmacol. Exp. Ther. 281, 460-463.

${ }^{6}$ Facino, R. M. Carini, M. Stefani, R. Aldini, G., Saibene, L. (1995) Arch. Pharm. 328, 720-724.

7 Reddy, K. G., Chandrakasan, Dhar, S. C. (1989) Biochem. Pharmacol. 38, 3527-3534.

${ }^{8}$ Reddy, K. G., Dhar, S. C. (1987) Ital. J. Biochem. 36, 205-217.

${ }^{9}$ Kapil, A., Moza, N. (1992) Int. J. Immunopharmacol. 14, 1139-1143.

10 Kapil, A., Sharma, S. (1994) J. Pharm. Pharmacol. 46, 922-923.

${ }^{11}$ Knaus, U., Wagner, H. (1996) Phytomedicine 3, 77-81.

12 Abe, N., Ebina, T., Ishida, N. (1982) Microbiol. Immunol. 26, $535-539$.

13 Shinada, M., Azuma, M., Kawai, H., Sazaki, K., Yoshida, I., Yoshida, T., Suzutani, T., Sakuma, T. (1986) Proc. Soc. Exp. Biol. Med. 181, 205-210.

${ }^{14}$ Zhang, Y. H., Isobe, K., Nagase, F., Lwin, T., Kato, M., Hamaguchi, M. Yokochi, T., Nakashima, I. (1993) Immunology 79, 528-534.

${ }^{15}$ Zhang, Y.-H., Kato, M., Isobe, K.-I., Hamaguchi, M., Yokochi, T., Nakashima, 1. (1995) Cell. Immunol. 162,97-104.

${ }^{16}$ Akamatsu, H., Komura, J., Asada, Y., Niwa, Y. (1991) Planta Med. $57,119-121$.

${ }^{17}$ Kiso, Y., Tohkin, M., Hikino, H. , Hattori, M., Sakamato, T., Namba, T. (1984) Planta Med. 50, 298-302.

18 Safayhi, H., Mack, T., Sabieraj, J., Anazodo, M. I., Subramanian, L. R., Ammon, H. P. T. (1992) J. Pharmacol. Exp. Ther. 261, 1143-1146.

19 Balanehru, S., Nagarajan, B. (1991) Biochem. Intern. 24, 981 -990.

${ }^{20}$ Balanehru, S., Nagarajan, B. (1992) Biochem. Intern. 28, 735-744.

21 Simon, A., Najid, A., Chulia, A. J., Delage, C., Rigaud, M. (1992) Biochim. Biophys. Acta 1125, 68-72.

22 Najid, A, Simon, A. Cook, H., Chable-Rabinovitch, H., Delage, C., Chulia, A. J., Rigault, M. (1992) FEBS Lett. 299, 213-217.

${ }^{23}$ Inoue, H., Saito, H., Koshihara, Y., Murato, S.-I. (1986) Chem. Pharm. Bull. 34, 879-901.

${ }^{24}$ Kweifio-Okai, G., Macrides, T. A. (1992) Res. Com. Chem. Pathol. Pharmacol. 78, 367-372.

25 Ammon, H. P. T., Mack, T., Singh, G. B., Safayhi, H. (1991) Planta Med. 57, 203-207

${ }^{26}$ Safayhi, H., Sailer, E. -R., Ammon, H. P. T. (1995) Mol. Pharmacol. $47,1212-1216$

${ }^{27}$ Sailer, E.-R., Subramanian, L. R., Rall, B., Hoernlein, R. F., Ammon, H. P. T., Safayhi, H. (1996) Br. J. Pharmacol. 117,615-618.

28 Sailer, E.-R., Hoernlein, R. F., Subramanian, L. R., Ammon, H. P. T., Safayhi, H. (1996) Arch. Pharm. Pharm. Med. Chem. 329, 54-56.

29 Batt, D. G. (1992) Progr. Med. Chem. 29, 1-63.

${ }^{30}$ Capasso, F., Mascolo, N., Autore, G., Duraccio, M. R. (1983) J. Pharm. Pharmacol. 35, 332-335.

31 Rask-Madsen, J., Bukhave, K., MAdsen, P. E. R., Bekker, C. (1983) Eur. J. Clin. Invest. 13,351-356.

32. Peskar, B. M. (1980) Scand. J. Gastroenterol. 15 (S 65), $109-112$.

33 Peskar, B. M., Holland, A., Peskar, B. A. (1976) J. Pharm. Pharmacol. $28,146-148$.

34 Peskar, B. M., Lange, K., Hoppe, U., Peskar, B. M. (1986) Prostaglandinds 31, 283-293.

35 Monder, C., Stewart, P. M., Lakshmi, V., Valentino, R., Burt, D., Edwards, C. R. W. (1989) Endocrinology 125, 1046-1053.

${ }^{36}$ Schleimer, R. P. (1991) Am. J. Respir. Cell. Mol. Biol. 4, 166-173.

37 Bühler, H., Perschel, F. H., Hierholzer, K. (1991) Biochim. Biophys. Acta 1075, 206-212.

38 Wang, B. H., Polya, G. M. (1995) Phytochemistry 41, 55-63.

${ }^{39}$ Fujioka, T., Kashiwada, Y., Kilkuskie, R. E., Cosentino, L. M., Ballas, L. M., Jiang, J. B., Janzen, W. P., Chen, I. -S., Lee, K. H. (1994) J. Nat. Prod. 57, 243-247.

${ }^{40}$ Pompei, R., Flore, O., Marccialis, M. A., Pani, A., Loddo, B. (1979) Nature 281, 689-690.

${ }^{41}$ Nose, M., Ito, M., Kamimura, K., Shimizu, M., Ogihara, Y. (1994) Planta Med. 60, 136-139.

42 Shibayama, Y. (1989) Exp. Molec. Pathol. 51, 48 -55.

43 Safayhi, H., Mack, T., Ammon, H. P. T. (1991) Biochem. Pharmacol. $41,1536-1537$
${ }^{44}$ Ma, X.-H., Zhao, Y. -C., Yin, L., Ji, C. X. (1982) Acta Pharm. Sin. 17, 93-97.

45 Han, D.-W., Ma, X.-H., Zhao, Y.-C., Yin, L. (1981) J. Tradit. Med. 2, $217-223$

${ }^{46}$ Lui, J., Liu, Y., Klaassen, C. D. (1994) J. Ethnopharmacol. 183-191.

47 Liu, J., Liu, Y.-P., Klaassen, C. D. (1995) Acta Pharmacol. Sin. 16, $97-102$

48 Liu, J., Liu, Y., Madhu, C., Klaassen, C. D. (1993) J. Pharmacol. Exp. Ther. 266, 1607-1613.

49 Liu, J., Liu, Y., Parkinson, A., Klaassen, C. D. (1995) J. Pharmacol. Exp. Ther. 275, 768-774.

50 Liu, Y., Kreppel, H., Liu, J., Choudhuri, S., Klaassen, C. D. (1993) J. Pharmacol. Exp. Ther. 266, 400-406.

51 Liu, J., Liu, Y., Mao, Q., Klaassen, C. D. (1994) Fund. Appl. Toxicol. $22,34-40$.

${ }^{52}$ Inoue, H., Inoue, K., Takeuchi, T., Nagata, N., Shibata, S. (1993) J. Pharm. Pharmacol. 45, 1067-1071.

${ }^{53}$ Singh, G. B., Singh, S., Bani, S., Gupta, B. D., Banerjee, S. K. (1992) J. Pharm. Pharmacol. 44, 456-458.

${ }^{54}$ Recio, M. C., Giner, R. M., Manez, S., Gueho, J., Julien, H. R., Hostettmann, K., Rios, J. L. (1995) Planta Med. 61, 9-12.

55 Sharma, M. L., Khajuria, A., Singh, S., Singh, G. B., Atal, C. K. (1988) Agents Actions 24, 161-164.

56 Singh, G. B., Atal, C. K. (1986) Agents Actions 18, 407-412.

57 Hirota, H., Mori, T., Yoshida, M., Iriye , R. (1990) Agric. Biol. Chem. $54,1073-1075$.

58 Huang, M. T., Ho, C. -T., Wang, Z. Y., Ferraro, T., Lou, Y.-R., Stauber, W. M., Georgiadis, C., Laskin, J. D., Conney, A. H. (1994) Cancer Res. 54, 701-708.

59 Yasukawa, K., Takido, M., Matsumoto, T., Takeuchi, M., Nakagawa, S. (1991) Oncology 48, 72-76.

${ }^{60}$ Akihisa, T., Yasukawa, K., Oinuma, H., Kasahara, Y., Yamanouchi, S., Takido, M., Kumaki, K., Tamura, T. (1996) Phytochemistry 43, $1255-1260$.

${ }^{61}$ Inoue, H., Mori, T., Shibata, S., Koshihara, Y. (1988) J. Pharm. Pharmacol. 40, 272-277.

62 Sharma, M. L., Bani, S., Singh, G. B. (1989) Int. J. Immunopharmacol. 11, 647-652.

63 Kumazawa, Y., Kawakita, T., Takimoto, H., Nomoto, K. (1990) Int. J. Immunopharmac. 12, 531-537.

${ }^{64}$ Konoshima, T., Kokumai, M., Kozuka, M., Tokuda, H., Nishino, H., Iwashima, A. (1992) J. Nat. Prod. 55, 1776-1778.

65 Delaveau, P., Lallouette, P., Tessier, A. M. (1980) Planta Med. 40, $49-54$.

${ }^{66}$ Sharma, M. L., Kaul, A., Khajuria, A., Sinh, S., Singh, G. B. (1996) Phytother. Res. 10,107-112.

67 Robson, J. M., Sullivan, F. M. (eds.) (1969) Carbenoxolone Sodium, Butterworth, London.

68 Symposium on clinical efficacy (1980) Scand. J. Gastroenterol. 15. Suppl. 65, 1-121.

69 Matsunami, H., Lynch, S. V., Balderson, G. A., Strong, R. W. (1993) Am. J. Gastroenterol. 88, 152-153.

${ }^{70}$ Lui, J. (1995) J. Ethnopharmacol, 49, 57-68.

71 Heldt, R. M., Winking, M., Simmet, T. (1996) Suppl. to Naunyn-S. Arch. Pharmacol. 353, Abstr. 538.

72 Böker, D.-K., Winking, M. (1997) Deutsches Ärzteblatt 94, A1 197-1199.

73 Von Keudell, C., Letzel, H., Koepcke, W., Kriegel, W., Wasserberg, S., Herborn, G., Heimstadt, P., Trabert, U., Etzel, R. (1994) Suppl. to Z. Rheumatol. 53 S, 36 Abst. V144.

${ }^{74}$ Etzel, R. (1996) Phytomedicine 3, 91 -94.

${ }^{75}$ Gupta, I., Parihar, A., Malhotra, P., Singh, G. B., Lüdtke, R., Safayhi, H., Ammon, H. P. T. (1997) Eur. J. Med. Res. 2, 1-7. 